\title{
Modeling Heat Transfer in Thin Fire Blanket Materials under High External Heat Fluxes
}

\author{
SHENG-YEN HSU ${ }^{1}$, JAMES S. T'IEN ${ }^{1}$, FUMIAKI TAKAHASHI ${ }^{1}$, and SANDRA OLSON ${ }^{2}$ \\ ${ }^{1}$ Mechanical and Aerospace Engineering \\ Case Western Reserve University \\ Cleveland, Ohio 44106, USA \\ ${ }^{2}$ NASA Glenn Research Center \\ Cleveland, Ohio 44135, USA
}

\begin{abstract}
To investigate the performance of thin fire blanket materials for house protection from wildland fires, a one-dimensional numerical model, which combines conductive and radiative heat transfer, has been developed, solved and compared with bench-scale experiments. Two types of incident heat sources are studied: convective heating from a burner flame and radiative heating from a cone heater. Radiative heat exchange between the blanket and the environment is critical in the performance of the blankets at high temperatures. The treatment of radiation includes the solution of the radiative transfer equation by the discrete ordinate method since in-depth absorbing, emitting and scattering are believed to be important in these thin blanket materials. A number of material combinations were tested and analyzed, including single and double layers of fiberglass fabric with and without aluminum foil on the front and back surfaces. It is found that high heat-blocking efficiencies can be obtained using thin blankets. Interestingly, it is also found that protecting a house from convective heating is a more difficult challenge than protecting it from radiant heating.
\end{abstract}

KEYWORDS: fire blanket, heat transfer, heat-blocking efficiency, wildfires.

\section{NOMENCLATURE}

$b \quad$ backward-scattering fraction factor

$C^{A} \quad$ apparent heat capacity $\left(\mathrm{J} / \mathrm{m}^{3} \cdot \mathrm{K}\right)$

$c_{p} \quad$ specific heat $(\mathrm{J} / \mathrm{kg} \cdot \mathrm{K})$

$G_{\text {chem }}$ energy generated by thermo-chemical reactions $\left(\mathrm{W} / \mathrm{m}^{3}\right)$

$h \quad$ convection heat transfer coefficient $\left(\mathrm{W} / \mathrm{m}^{2} \cdot \mathrm{K}\right)$

$i \quad$ radiation intensity $\left(\mathrm{W} / \mathrm{m}^{2}\right)$

$k \quad$ thermal conductivity $(\mathrm{W} / \mathrm{m} \cdot \mathrm{K})$

$L_{\text {end }} \quad$ model domain distance $(\mathrm{m})$

$L_{f} \quad$ blanket thickness (m)

$Q_{\text {conv }} \quad$ convective heat source $\left(\mathrm{W} / \mathrm{m}^{2}\right)$

$Q_{\text {rad }}$ radiative heat source $\left(\mathrm{W} / \mathrm{m}^{2}\right)$

$q \quad$ heat flux $\left(\mathrm{W} / \mathrm{m}^{2}\right)$

$S \quad$ coordinate along the path of radiation (m)

$\hat{s} \quad$ unit vector

$T$ temperature (K)

$t$ time (s)

$x \quad x$-directional coordinate $(\mathrm{m})$

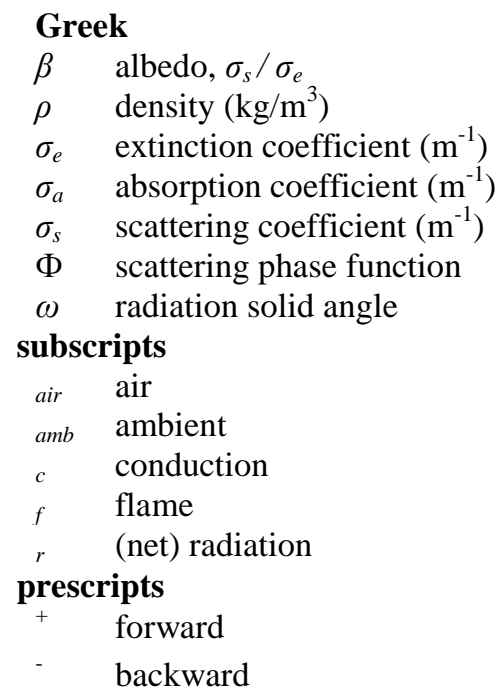

\section{INTRODUCTION}

Thermal resistant fibers have been widely used as insulation materials for blankets and garments for fire protection. In firefighter's protective clothing, multiple layers of different materials may be employed. To protect a person from heat injury, the inside of the clothing has to be at a sufficient low temperature. The clothing is therefore quite thick with good insulating property and large thermal inertia. These properties keep the cloth inside temperature low for a period of time for the firefighter to perform their duty or to 
escape. Clearly, the thicker the clothing, the longer will be the period of safe operation. The firefighter's clothing is quite thick, most commonly with three layers: shell, moisture barrier and thermal liner [1].

Fire blankets have also been proposed to protect houses in wildland fires [2-6]. In this application, the entire house is covered with the fire blanket before the fire's arrival. The objective is to prevent ignition of the house. Deployment difficulties and economic concerns rule out the use of thick blankets. Thin blankets, on the other hand, may not be effective as a heat conduction barrier since their small thermal inertia gives a short transient period. Take a typical high-temperature resistant fabric material (aramid/fiberglass) with a thickness of $1.65 \mathrm{~mm}$, for example. The transient heat-up time is approximately $20 \mathrm{~s}$ in the thermal protective performance (TPP) test. A house may need to be protected from a passing wildland fire for an hour including $10 \mathrm{~min}$ or more of intense heat flux. Because the thermal response time of the blanket is much shorter than the time scale of the incident heat input, the blanket thermal response can be approximated as a series of quasi-steady states. To be effective, the house fire blanket has to have a superior performance in the steady or quasi-steady states. This is fundamentally different from the operation of firefighter's clothing where the useful period is in the transient heat-up stage.

In steady state, protection cannot be based on the mechanism of low material heat conduction alone. If conduction is the only heat transfer mode, all the heat input from the external fire will go through the blanket at steady state. If we define a steady-state heat blocking efficiency (HBE) as one minus the ratio of the transmitted heat flux to the incident heat flux, HBE is zero in this case. Clearly, to have a high HBE, other heat blocking mechanisms are required. It turns out that radiation can provide such a mechanism.

Unlike personnel protection, the inside of the fire blanket for a house can tolerate a relatively high temperature without causing ignition. This temperature can reach several hundred degrees centigrade. In this temperature range, radiation becomes significant, so the heat rejection by radiation can become an effective means to protect the house.

In a given wildland fire scenario, a house may first be subject to a conductive heat flux by wind-blown embers bombarding the roof even when the fire is still far away and then a radiative and convective heat flux when the fire reaches the house. So, all three heat transfer modes, conduction, convection and radiation, can serve as the externally applied heat input to the blanket. In this work, we will examine the blanket performance subject to a high convective or radiative heat source. It is believed that if the blanket can protect subjects in high convective heating, it should be able to do the same in the conductive heating induced by falling embers.

\section{Radiative Heating vs. Convective Heating}

The best way to reduce the penetration of external radiation heat input is to have a highly reflective surface, an aluminum sheet for example. On the other hand, the only way to reduce penetration from convective heat input in steady state is to lose heat by radiative emission from the front surface. Two different material radiative properties are thus demanded. To design a fire blanket that could be subjected to both types of heat fluxes may require composite layers of materials optimized to take advantage of the possibility that material property may change during heating. For example, when the surface temperature becomes too high, a charring surface may give higher radiative emission loss.

In this work, both the blanket responses to radiative and to convective heat sources are investigated. The high-temperature resistant fabrics are $100 \%$ fiberglass with or without an aluminum foil attached to one side. This study includes both experiments and modeling. Because radiation is crucial to the success of fire blanket function, a rigorous heat transfer model including both conduction and radiation is used. For thin materials such as the one considered here, radiation is not limited to the surface. In-depth absorption and emission are considered. A radiation transfer equation is solved that contains absorption, emission and scattering terms.

Since the model will be compared with two sets of laboratory bench-scale experiments (one with primarily radiative heat flux and the other with primarily convective heat flux), the experimental set-ups will be briefly mentioned first. More details can be found elsewhere [2-6]. 


\section{EXPERIMENTAL SET-UP}

The external convective heat flux is provided by a modified propane-fueled Meker burner [7] and the radiative heat flux from an upward-facing radiant cone heater [8]. Figure 1 shows the schematic of the sample holder, which also shows the placement of the thermocouples and the backside heat flux transducer. The fabric specimens are cut to $150 \mathrm{~mm}$ by $150 \mathrm{~mm}$ strips and placed horizontally between a stainless steel mounting plate and a spacer (6.4 mm thickness). The sample's exposed area is $51 \mathrm{~mm}$ by $51 \mathrm{~mm}$ square. Thermocouples are positioned touching the front-side (lower) and back-side (upper) surfaces of the fabric (Type-K, $0.020^{\prime \prime}(0.51 \mathrm{~mm})$ sheath diameters; unexposed and exposed beads, respectively). This holder is then mounted $52 \mathrm{~mm}$ above the burner surface or $25 \mathrm{~mm}$ above the cone heater's exit plane.

The data reported in this paper are for a radiative flux at $83 \mathrm{~kW} / \mathrm{m}^{2}$ from the cone heater and for the convective heat flux initially also at $83 \mathrm{~kW} / \mathrm{m}^{2}$ from the Meker burner when the front surface temperature of the sample is at room temperature. For the convective heating, as the sample heats up, the heat flux changes due to the decreasing temperature difference between the flame and the sample and the convection heat transfer coefficient. Note that $83 \mathrm{~kW} / \mathrm{m}^{2}$ is used as the standard in thermal protective performance (TPP) test for firefighters' clothes.

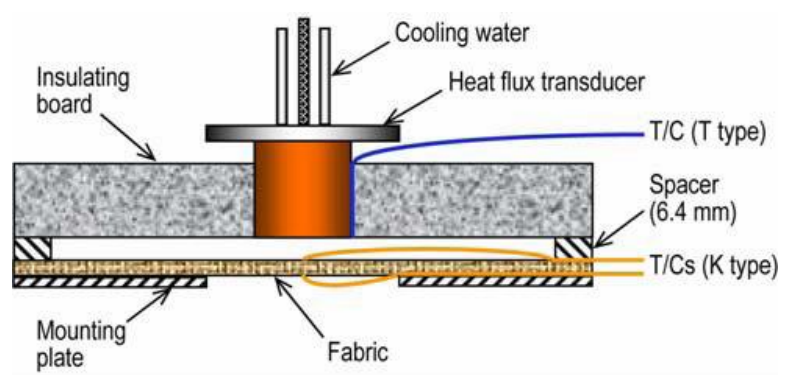

Fig. 1. A schematic of an assembly of a fabric specimen holder and a heat flux transducer.

Experimental data and computed results (dashed lines) are shown in Fig. 2 for a single-layer fiberglass fabric. The data include front and back side temperatures and transmitted heat flux as a function of time. Out of these three data, we believe the heat flux data is the most reliable and reproducible. The thermocouple measurement at high temperature for thin fabric samples with large temperature gradient introduces uncertainties due to the different contact pressure and position variation in the heterogeneous structure of the fabric. The degree of contact can vary during the heating process. An example is shown in Fig. 2b. While the front temperature and transmitted heat flux remain at steady values after the first $20 \mathrm{~s}$, the back temperature continues falling. The second related uncertainty is the thermocouple radiation correction since the thermocouple and the blanket may have different emissivity. Consequently in the later model comparison with experiments, more emphasis will be placed on the heat-blocking efficiency (HBE) while the recorded temperatures are used as a supplementary data source.

\section{HEAT TRANSFER MODEL}

\section{Previous Models}

While there are numerous modeling works on thicker firefighter's protective clothing at low temperature (e.g. [1,9-11]), there is little work on high temperature fabrics. In the only works we are aware of, Torvi et al. $[12,13]$ developed a one-dimensional model to simulate the flame-resistant fabrics subjected to the high heat fluxes in Meker burner tests. In their model, in addition to conduction, radiation is treated by using Beer's law for in-depth absorption and emission. The way emission is treated is that the total emission from the front surface is computed using surface temperature and surface emissivity. The local emissive energy is then distributed in-depth according to the Beer's law. This model was adopted in our earlier works for the fire blanket [4-6] but it has since been found that this simplified radiation model (e.g. surface emissivity, surface reflectivity and transmissivity) is not sufficiently accurate for a thin fabric at high temperatures with a large temperature gradient. Therefore, an improved treatment of radiation is desirable. 


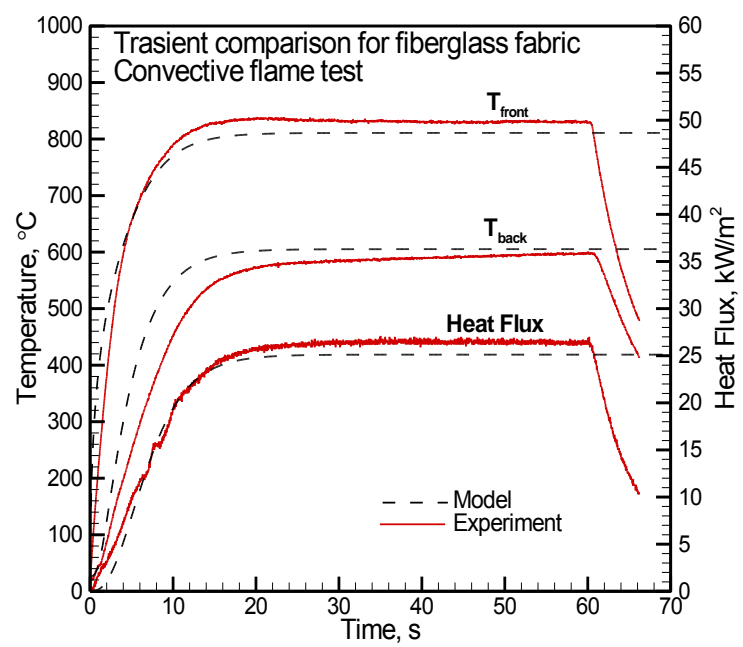

(a)

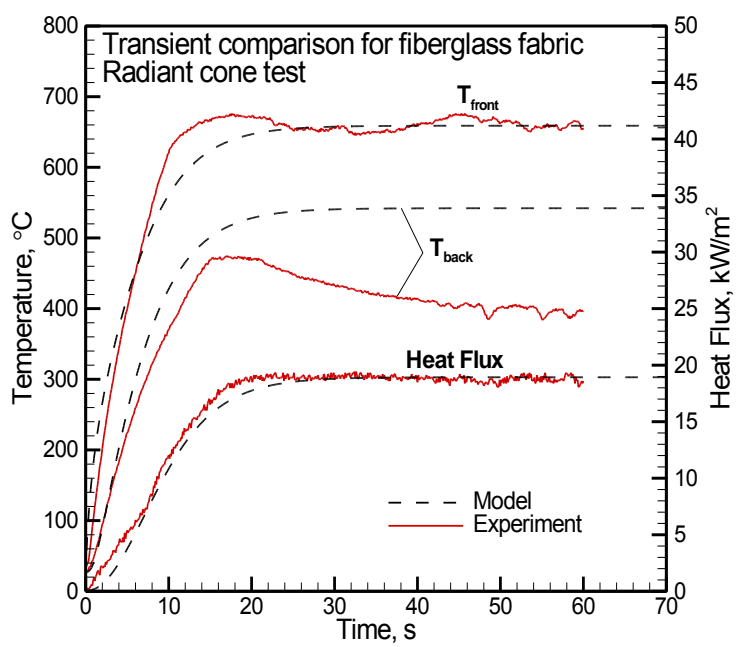

(b)

Fig. 2. The comparison of heat flux, front- and back-side temperatures between experimental measurements and model results for the fiberglass fabric (Case \#1 in Table 3) in: (a) convective Meker burner test; (b) radiant cone test.

A brief review of the various heat transfer models for fibrous materials has been given by Tong and Tien [14] and Petrov [15]. Basically, there are two approaches in calculating the radiant heat flux: 1.) to employ a radiative conductivity or model radiation as a conductive process. 2.) to solve the equation of radiative heat transfer governing the intensity of radiation in an absorbing, emitting and scattering medium. Due to the mathematical simplicity, the first method is widely used (e.g. Torvi et al.'s model $[12,13])$. However, its treatment of radiation transfer is less accurate. In addition, the experimentally measured total (apparent) conductivity may depend on temperature drop, thickness of sample, properties of boundaries and time parameters at transient condition. Therefore, although the second method of solving the radiation transfer equation is more complex, it has been adopted for the application of low weight fibrous insulations. Tong and Tien [16] introduced three radiative properties of fibers in their one-dimensional radiation model: absorption coefficient $\left(\sigma_{a}\right)$, scattering coefficient $\left(\sigma_{s}\right)$ and backward-scattering fraction factor $(b)$ (which will be described later). The volumetric radiation properties of the fabrics, i.e. emittance (absorptance), reflectance and transmittance, can be computed from the solution of the radiation transfer equation based on these properties and the sample thickness. In the present model for high temperature fire blankets, the solution of the radiation transfer equation will be sought.

\section{Model Description}

The configuration of the one-dimensional heat transfer model for the two tests is shown in Fig. 3. This is similar to that shown in the experimental assembly in Fig. 1. The model includes two parts: blanket and air gap spacer. The blanket sample may consist of multiple layers of similar or different materials. For example, fiberglass fabric may have an aluminum foil on the front or on the back (an adhesive layer is not included for simplicity). Two layers of fiberglass fabric may stack up with or without aluminum foil according to the schematic in Fig. 3. The conductive heat source or the radiative heat source is applied at the front exposed surface $(x=0)$. The heat can transfer by radiation and conduction through the blanket. In the $6.4 \mathrm{~mm}$ air gap spacer, the natural convection can be ignored because of the low Rayleigh number $(R a<1708)$ [17] and only conduction is considered. Radiation between the blanket and the heat flux transducer is also considered. 


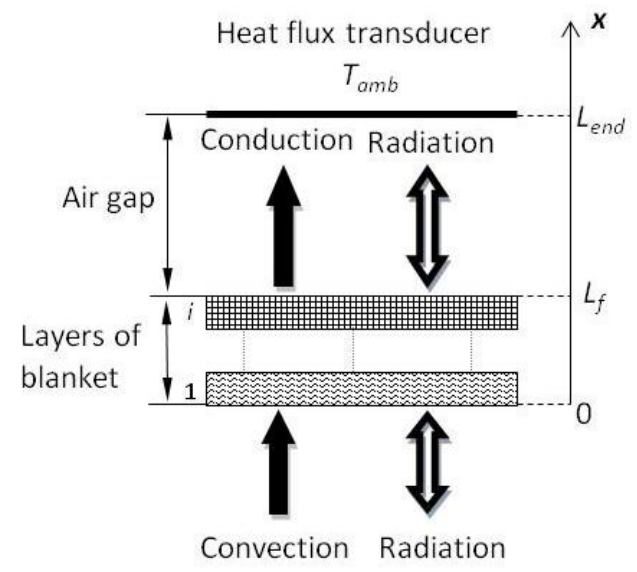

Fig. 3. One-dimensional configuration of fire blanket model.

Under high heat fluxes, the fabric materials can reach several hundreds of Celsius degrees in seconds and thermo-chemical reactions are possible at these high temperatures. The fabrics may become char, tar, etc., and therefore, the thermal properties may greatly depend on temperature. By neglecting the convective heat transfer in the blanket and air gap, the governing energy equation can express as:

$\rho(T) c_{p}(T) \frac{\partial T}{\partial t}=\frac{\partial}{\partial x}\left(k(T) \frac{\partial T}{\partial x}\right)-\frac{\partial q_{r}}{\partial x}+G_{c h e m}$

where $\rho, c_{p}$ and $k$ are density, heat capacity and thermal conductivity, which are functions of temperature. $G_{c h e n}$ is the energy generated by thermo-chemical reactions in the fabric per unit volume. $q_{r}$ is the net radiative heat flux resolved from the equation of radiative heat transfer.

In order to easily implement the property changes and reactions, the apparent heat capacity method, which can incorporate $G_{c h e m}$ into the value of the volumetric heat capacity $\left(\rho \cdot c_{p}\right)$, is suggested for use in the model [12] instead of treating phase changes, tracking the location of the moving boundary. Equation 1 is suggested to be written as:

$C^{A}(T) \frac{\partial T}{\partial t}=\frac{\partial}{\partial x}\left(k(T) \frac{\partial T}{\partial x}\right)-\frac{\partial q_{r}}{\partial x}$

where $C^{A}$ is the apparent heat capacity. It should be mentioned that the thermal conductivity used in the model may need to be corrected because the radiative heat transfer is usually included in the measurement of fibrous materials especially at high temperatures.

The net radiation heat flux is given by:

$q_{r}(x)=\int_{4 \pi} i(x, \hat{s}) \hat{s} d \omega$

where $i$ is the radiation intensity, $\hat{s}$ is unit vector and $\omega$ is the radiation solid angle. The radiation intensity, $i$, is obtained from the solution of the radiation transfer equation:

$\frac{d i}{d S}=-\sigma_{a}(S) i(S)+\sigma_{a}(S) i_{b}(S)-\sigma_{s}(S) i(S)+\frac{\sigma_{s}(S)}{4 \pi} \int_{\omega_{i}}^{4 \pi} i\left(S, \omega_{i}\right) \Phi\left(\omega, \omega_{i}\right) d \omega_{i}$ 
where $S$ is the coordinate along the path of radiation, $\sigma_{a}$ is absorption coefficient, $\sigma_{s}$ is scattering coefficient and $\Phi$ is the scattering phase function. A gray medium is assumed. In addition, the scattering pattern is only divided into forward scattering and backward scattering in the one-dimensional analysis. Instead of using complex directional dependence, a backward-scattering fraction factor $b$, the ratio of backward scattering to total scattering, is applied [16].

To sum up, there are five parameters in the blanket heat transfer model, which are $C^{A}, k, \sigma_{a}, \sigma_{s}$ and $b$. Thermal inertia $C^{A}$ only affects the transient response. In steady state, only the last four properties are important. Out of the four, three are radiation parameters. Alternatively, $\sigma_{a}$ and $\sigma_{s}$ are sometimes expressed by the extinction coefficient $\left(\sigma_{e}=\sigma_{a}+\sigma_{s}\right)$ and the albedo $\left(\beta=\sigma_{s} / \sigma_{e}\right)$.

The ambient temperature $300 \mathrm{~K}$ is set as the initial condition in the entire domain. As $\mathrm{t}>0$, for the radiative heating, the boundary condition for Eq. 4 at the front surface $(x=0)$ is:

$\left.q_{r}^{+}\right|_{x=0}=Q_{\text {rad }}$

where $\left.q_{r}^{+}\right|_{x=0}$ is the forward radiative heat flux at $x=0$ and $Q_{\text {rad }}$ is incident heat flux from the radiative heat source. No convective cooling is considered at the front surface for radiative heating due to the large size of the horizontal sample. For convective heating from the Meker burner, the boundary condition for Eq. 2 at the front surface $(x=0)$ is:

$-\left.k \frac{\partial T}{\partial x}\right|_{x=0}=Q_{\text {conv }}=h_{f}\left(T_{f}-T_{x=0}\right)$

where $Q_{\text {conv }}$ is the heat flux from the convective heat source, $h_{f}$ is the convection heat transfer coefficient, $T_{f}$ is the flame temperature and $T_{x=0}$ is the blanket front surface temperature. The value of $h_{f}$ is initially calibrated by $Q_{\text {conv }} /\left(T_{f}-T_{\text {amb }}\right)$ based on an estimated flame temperature $T_{f}=2000 \mathrm{~K}$ [12] and the applied heat flux $\left(Q_{c o n v}=83 \mathrm{~kW} / \mathrm{cm}^{2}\right)$ measured by a water-cooled heat flux transducer. Since $h_{f}$ is proportional to the gas conductivity which is temperature dependent, its value should increase as the blanket surface increases during heating. An expression for $h_{f}$ is thus derived based on the above two sets of information. This expression is listed in Table 1. Note that in computing the HBE for the convective heating case, the incident heat flux is always based on the initial rating of the burner, i.e. the value when the blanket surface temperature $T_{x=0}=300 \mathrm{~K}$.

Table 1. Heat flux source parameters.

\begin{tabular}{|c|c|c|c|}
\hline & Unit & Convective source & Radiative source \\
\hline$T_{f}$ & $\mathrm{~K}$ & 2000 & - \\
\hline$h_{f}$ & $\mathrm{~kW} / \mathrm{m}^{2} \cdot \mathrm{K}$ & $0.0488 \cdot \frac{\left.k_{a i r}\left(T_{f}+T_{x=0}\right) / 2\right)}{k_{\text {air }}(1150 \mathrm{~K})}$ & - \\
\hline$Q_{\text {rad }}$ & $\mathrm{kW} / \mathrm{m}^{2}$ & - & 83 \\
\hline$T_{a m b}$ & $\mathrm{~K}$ & 300 & 300 \\
\hline
\end{tabular}

The boundary condition at the surface of the transducer $\left(x=L_{\text {end }}\right)$ for Eq. 2 is fixed at room temperature $\left(T_{a m b}\right)$ and the backward radiative heat flux at the back surface of fire blanket $\left(\left.q_{r}^{-}\right|_{x=L_{f}}\right)$ for Eq. 4 depends on the surface temperature of the transducer:

$$
\begin{aligned}
& \left.T\right|_{x=L_{\text {end }}}=T_{a m b} \\
& \left.q_{r}^{-}\right|_{x=L_{f}}=\sigma T_{a m b}^{4}
\end{aligned}
$$




\section{Numerical Method}

The differential heat transfer equation (Eq. 2) is discretized by using the control volume method and linearized by using a finite-difference technique. The linear matrix is solved by using a tri-diagonal matrix algorithm. In addition, an unconditionally stable fully-implicit scheme is used for the unsteady term. The radiation transfer equation (Eq. 4) is solved by the $\mathrm{S}_{\mathrm{N}}$ discrete ordinate method [18].

The grid size effect is dominated by the highly nonlinear radiation equation. The non-dimensional grid size $\left(\sigma_{e} d x\right)$ in the fabric is set to be 0.3 , the time step is $0.1 \mathrm{~s}$ for Eq. 2 . The six direction Gaussian quadrature set for angular discretizaion is used for solving Eq. 4. For those cases with a thin aluminum layer, only one grid is needed in the aluminum layer since the temperature difference across the aluminum foil is negligible due to its high thermal conductivity and foil thinness. For the air gap between two fabrics, only 5 grids are used because it is optically thin. All the numerical parameters have been tested for grid independence.

\section{Choice of Properties Values}

The fiber material is $100 \%$ fiberglass with or without an aluminum foil attached to one side. The radiative properties of blankets depend on the fiber materials (chemical composition) and the physical structure (fiber size, the volume fraction of fibers and weaving methods). To the authors' knowledge, radiative property data of the fiberglass fabric needed for the model computation do not exist. Therefore, insulation fiberglass, of a similar chemical composition, is chosen to help determine part of the radiative properties since they have been extensively studied [16,19,20] Additional property values are further optimized by comparing model results and experimental data for two simple cases, a single layer of fiberglass fabric and a single layer of aluminized fiberglass fabric (Cases \#1 and \#2 in Table 3).

Table 2. The property parameters of fiberglass fabric, aluminum foil and air gap between two fabrics.

\begin{tabular}{|c|c|c|c|c|c|c|}
\hline & $\begin{array}{c}\text { Thickness, } \\
L_{f}(\mathrm{~mm})\end{array}$ & $\begin{array}{c}\text { Apparent heat } \\
\text { capacity, } \\
\mathbf{C}^{\mathrm{A}}\left(\mathbf{k J} / \mathbf{m}^{3} \cdot \mathbf{K}\right) \\
\end{array}$ & \begin{tabular}{|c|} 
Thermal \\
conductivity, \\
$k(\mathrm{~W} / \mathbf{m} \cdot \mathrm{K})$ \\
\end{tabular} & $\begin{array}{c}\text { Extinction } \\
\text { coefficient, } \\
\sigma_{e}\left(\mathbf{c m}^{-1}\right) \\
\end{array}$ & $\begin{array}{c}\text { Albedo, } \\
\boldsymbol{\beta}\end{array}$ & $\begin{array}{c}\text { Scattering } \\
\text { pattern, } \\
b \\
\end{array}$ \\
\hline Fiberglass fabric & $0.91^{\mathrm{a}}$ & $\begin{array}{c}557+0.23345 \\
(T-300 \mathrm{~K})\end{array}$ & $\begin{array}{c}0.06+0.00007 \\
(T-300 \mathrm{~K})\end{array}$ & $235^{\mathrm{b}}$ & 0.9 & $0.35^{\mathrm{c}}$ \\
\hline \multirow{2}{*}{ Aluminum foil } & \multirow{2}{*}{$0.025^{\mathrm{a}}$} & \multirow[b]{2}{*}{-} & \multirow[b]{2}{*}{-} & $\begin{array}{c}2800, \\
\mathrm{~T}<610^{\circ} \mathrm{C}\end{array}$ & \multirow{2}{*}{0.93} & \multirow{2}{*}{1.0} \\
\hline & & & & $\begin{array}{c}380, \\
\mathrm{~T}>710^{\circ} \mathrm{C}\end{array}$ & & \\
\hline $\begin{array}{c}\text { Air gap between } \\
\text { two fabrics }\end{array}$ & 0.5 & Standard table & Standard table & - & - & - \\
\hline
\end{tabular}

\footnotetext{
${ }^{\mathrm{a}}$ Measured.

${ }^{\mathrm{b}}$ Refer to Ref. [19]

${ }^{\mathrm{c}}$ Refer to Ref. [16]
}

Table 2 shows the property parameters chosen for the fiberglass fabric. The value of the extinction coefficient $\left(\sigma_{e}=\sigma_{a}+\sigma_{s}\right)$ is obtained according to the mass extinction coefficient equal to $34.7 \mathrm{~m}^{2} / \mathrm{kg}$ measured in Ref. [19]. For the scattering pattern, Lee [21] found that the phase function for fibrous media always exhibits a strong peak in the direction of incident radiation, indicating that the scattering is highly forward. In addition, Tong and Tien also found that the backward scattering factors of the silica fibrous insulations are between 0.25 and 0.45 over a wide range of wavelengths [16]. So, the back-scattering fraction factor $b$ is assumed equal to 0.35 .

The value of the apparent thermal conductivity is obtained by curve-fitting the four data points furnished by the manufacturer $\left(0.0596 \mathrm{~W} / \mathrm{m} \cdot \mathrm{K}\right.$ at $22.8{ }^{\circ} \mathrm{C} ; 0.1030 \mathrm{~W} / \mathrm{m} \cdot \mathrm{K}$ at $232.8{ }^{\circ} \mathrm{C} ; 0.1268 \mathrm{~W} / \mathrm{m} \cdot \mathrm{K}$ at $343.9{ }^{\circ} \mathrm{C}$; $0.1601 \mathrm{~W} / \mathrm{m} \cdot \mathrm{K}$ at $482.8{ }^{\circ} \mathrm{C}$ ) using ASTM C177-97 [22]. However, as mentioned before, at high temperatures the experimentally measured thermal conductivity includes the effect of radiation in the fibrous media (that is why it is referred to as the apparent thermal conductivity). In the present work, only the measured thermal conductivity at low temperature $(\sim 0.06 \mathrm{~W} / \mathrm{m} \cdot \mathrm{K}$ at $300 \mathrm{~K})$, where the radiation effect is negligible, is used. For higher temperatures, thermal conductivity is assumed to increase linearly with 
temperature. The proportional constant is treated as a parameter and together with the radiation property albedo is adjusted to fit the experiment data of fiberglass in Case \#1. According to the best fit (Fig. 2), the liner temperature coefficient of the thermal conductivity and albedo are respectively equal to $7 \times 10^{-5} \mathrm{~W} / \mathrm{m} \cdot \mathrm{K}^{2}$ and 0.9 . The value of albedo $(0.9)$ is reasonable for the high-scattering fiber glass materials at high temperatures [16,20]. In addition, It is assumed that there is no fabric mass loss and no heat generated by thermo-chemical reactions, so the apparent heat capacity $C^{A}$ is equal to $\rho \cdot c_{p}$ here, which is adjusted to fit the transient measurements in Case \#1. It should be noted that the steady-state HBE is independent of the value of the apparent heat capacity. After these fiberglass properties are calibrated, they are kept fixed for all the computations in the other cases.

Table 3. The comparison of steady-state heat-blocking efficiency (HBE) between experiments and model simulations.

\begin{tabular}{|c|c|c|c|c|c|c|c|c|c|c|c|c|c|c|}
\hline \multirow{3}{*}{$\begin{array}{l}\text { Fiberglass } \\
\text { fabric: } \\
\text { Al foil: }\end{array}$} & \multirow{3}{*}{\multicolumn{2}{|c|}{$\begin{array}{c}\text { Case No. } \\
\text { and } \\
\text { blanket } \\
\text { construction }\end{array}$}} & \multicolumn{6}{|c|}{ Convective flame } & \multicolumn{6}{|c|}{ Radiant cone } \\
\hline & & & \multicolumn{3}{|c|}{ Experiment } & \multicolumn{3}{|c|}{ Model } & \multicolumn{3}{|c|}{ Experiment } & \multicolumn{3}{|c|}{ Model } \\
\hline & & & $\begin{array}{r}\mathrm{HBE} \\
(\%)\end{array}$ & $\begin{array}{l}T_{\text {front }} \\
\left({ }^{\circ} \mathrm{C}\right)\end{array}$ & $\begin{array}{l}T_{b a c} \\
\left({ }^{\circ} \mathrm{C}\right)\end{array}$ & $\begin{array}{c}\mathrm{HBE} \\
(\%)\end{array}$ & $\begin{array}{l}T_{\text {front }} \\
\left({ }^{\circ} \mathrm{C}\right)\end{array}$ & $\begin{array}{l}T_{\text {back }} \\
\left({ }^{\circ} \mathrm{C}\right)\end{array}$ & $\begin{array}{l}\mathrm{HBE} \\
(\%)\end{array}$ & $\begin{array}{l}T_{\text {front }} \\
\left({ }^{\circ} \mathrm{C}\right)\end{array}$ & $\begin{array}{l}T_{\text {back }} \\
\left({ }^{\circ} \mathrm{C}\right)\end{array}$ & $\begin{array}{c}\mathrm{HBE} \\
(\%)\end{array}$ & $\begin{array}{l}T_{\text {front }} \\
\left({ }^{\circ} \mathrm{C}\right)\end{array}$ & $\begin{array}{l}T_{\text {back }} \\
\left({ }^{\circ} \mathrm{C}\right)\end{array}$ \\
\hline \multirow{2}{*}{$\begin{array}{l}\text { Single } \\
\text { layer }\end{array}$} & 1 & 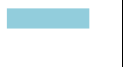 & 68.2 & 837 & 601 & 69.7 & 811 & 605 & 75.2 & 608 & 383 & 77.4 & 659 & 542 \\
\hline & 2 & 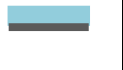 & 59.2 & 939 & 710 & 60.1 & 894 & 670 & 93.3 & 525 & 244 & 93.7 & 357 & 306 \\
\hline \multirow{4}{*}{$\begin{array}{c}\text { Double } \\
\text { layers }\end{array}$} & 1 ' & 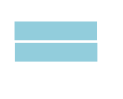 & 77.9 & 820 & 408 & $\begin{array}{c}80.1 \\
(77.7)\end{array}$ & $\begin{array}{c}851 \\
(842)\end{array}$ & $\begin{array}{c}514 \\
(537)\end{array}$ & 86.0 & 630 & 415 & $\begin{array}{c}84.2 \\
(82.4)\end{array}$ & $\begin{array}{c}707 \\
(696)\end{array}$ & $\begin{array}{l}466 \\
(488)\end{array}$ \\
\hline & 2 , & & 75.0 & 875 & 440 & 72.7 & 961 & 582 & 92.9 & 516 & 299 & 94.1 & 425 & 295 \\
\hline & 3 , & 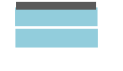 & 79.8 & 899 & 485 & 88.8 & 881 & 679 & 90.9 & 717 & 597 & 91.6 & 750 & 631 \\
\hline & 4 & & 87.9 & 851 & 510 & 78.8 & 990 & 705 & 96.2 & 569 & 397 & 95.2 & 554 & 464 \\
\hline
\end{tabular}

ps1: ( ) no air gap.

ps2: The melting point of aluminum is $660^{\circ} \mathrm{C}$. In the model, the extinction coefficient of aluminum foil linearly changes between $610^{\circ} \mathrm{C} \sim 710^{\circ} \mathrm{C}$.

\section{COMPUTATIONAL RESULTS AND COMPARISON WITH EXPERIMENTAL DATA}

A number of different arrangements of fiberglass fabric and aluminum foil have been computed and tested. This includes single fabric with or without aluminum foil on the front surface and double layers of fiberglass fabric with or without aluminum foils on the front and on the back surfaces. These combinations are listed in Table 3.

Figures $2 \mathrm{a}$ and $2 \mathrm{~b}$ respectively show the comparisons between numerical results and experimental measurements in the Meker burner convection test and cone heater radiation test for the single layer of fiberglass fabric (Case \#1 in Table 3). The agreement is very good partially because this is the case used to calibrate some of the model parameters. The comparison of the heat-blocking efficiency (HBE), which is defined as [1-(transmitted heat flux) / (incident heat flux)], are also very favorable (model $69.7 \%$ vs. experiment $68.2 \%$ in convective flame test and model $77.4 \%$ vs. experiment $75.2 \%$ in radiant cone test) as can be seen in Table 3 . We have earlier discussed the discrepancy of the back side temperature measurement. 


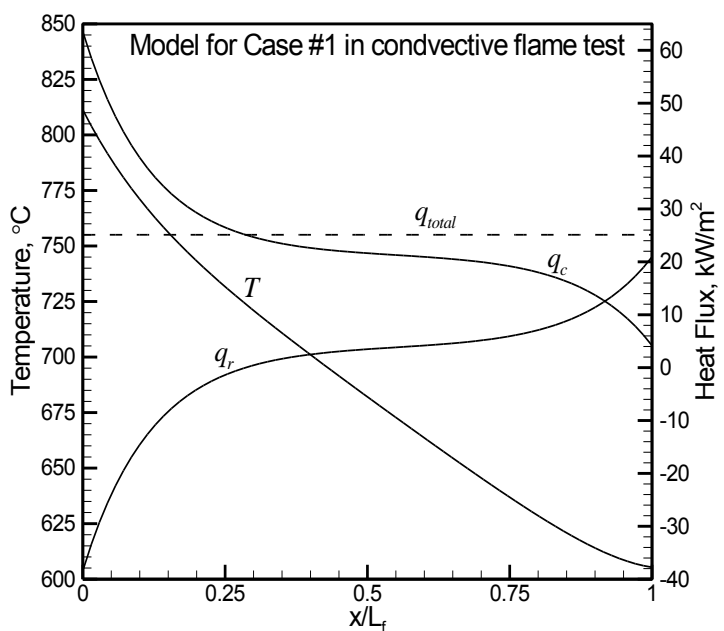

(a)

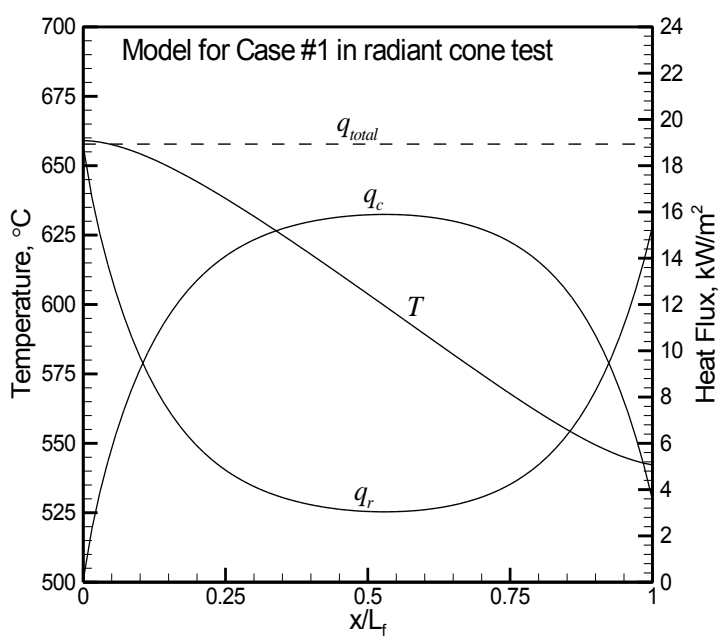

(b)

Fig. 4. Case \#1 in Table 3. The computed distributions of temperature $(T)$, conductive heat flux $\left(q_{c}\right)$, net radiative heat flux $\left(q_{r}\right)$ and total heat flux in the fiberglass fabric at the steady state in: (a) convective flame test; (b) radiant cone test.

Figure 4 shows the computed distributions of temperature, convective heat flux $\left(q_{c}\right)$, net radiative heat flux $\left(q_{r}\right)$ and total heat flux $\left(q_{\text {total }}=q_{c}+q_{r}\right)$ inside the fabric at steady state for Case \#1. These interior distributions are difficult to obtain experimentally but can reveal a physical insight into how blanket is functioning. In the convective flame test (Fig. 4a), the heat going into the blanket is reduced by radiation emission from the heated layer. Figure $4 \mathrm{a}$ shows that in the blanket front surface region up to $0.28 L_{f}, q_{r}$ is negative, meaning the net radiation goes toward the front surface. In-depth radiation in the region results in a radiative loss from the blanket that reduces the total heat flux to $\sim 25 \mathrm{~kW} / \mathrm{m}^{2}$. Note that the total heat flux $\left(q_{\text {total }}\right)$ is uniform across the fabrics since this is a steady analysis and $q_{\text {total }}$ is also the transmitted heat flux through the blanket. Recall $q_{\text {total }}=q_{c}+q_{r}$, the distributions between $q_{c}$ and $q_{r}$ vary along the depth of the blanket. In the interior, $q_{r}$ is nearly zero but its magnitude increases near the surfaces. Because the temperature close to the back surface is lower than that close to the front surface, the magnitude of $q_{r}$ is greater near the front surface. This greater heat loss from the front surface is the main heat blocking mechanism for the blanket in steady (or quasi-steady) state. It is also interesting to see that in the present case, the transmitted heat at the back surface is more by radiation than conduction $\left(21 \mathrm{vs} .4 \mathrm{~kW} / \mathrm{m}^{2}\right)$. The computed HBE in this case is $69.7 \%$.

Using the same fiberglass fabric but subject to an incident radiative heat flux of $83 \mathrm{~kW} / \mathrm{m}^{2}$, Fig. $4 \mathrm{~b}$ shows a very different heat transfer phenomenon from the convective flame test (Fig. 4a). The magnitudes of temperatures and the temperature gradients (especially close to the front surface $(x=0)$ ) are different. The distributions of $q_{c}$ and $q_{r}$ are drastically different. Part of the incident radiation is reflected (backward scattering in our model) and with emission loss from the high temperature zone near the front surface, the net radiation entering into the blanket is only $\sim 19 \mathrm{~kW} / \mathrm{m}^{2}$. At the front surface $q_{c}$ is zero so $q_{\text {total }}=q_{r}$. Note that different from the convective heating case, $q_{r}$ is positive near the front surface region, i.e. going into the interior and being absorbed. After reaching a minimum near the center of the fabric, its magnitude increases due to in-depth emission toward the back surface. The distribution of $q_{c}$ shows the opposite trend. The transmitted heat flux is $\sim 15 \mathrm{~kW} / \mathrm{m}^{2}$ radiation and $\sim 3.8 \mathrm{~kW} / \mathrm{m}^{2}$ conduction, again dominated by radiation. The computed $\mathrm{HBE}$ is $77.4 \%$ which is higher than that in the convective test. As is seen in Table 3, for all the cases examined, convective cases have a lower HBE than the radiative cases. Therefore, protecting houses from convective heating is a more challenging task than protecting them from radiative heating. 


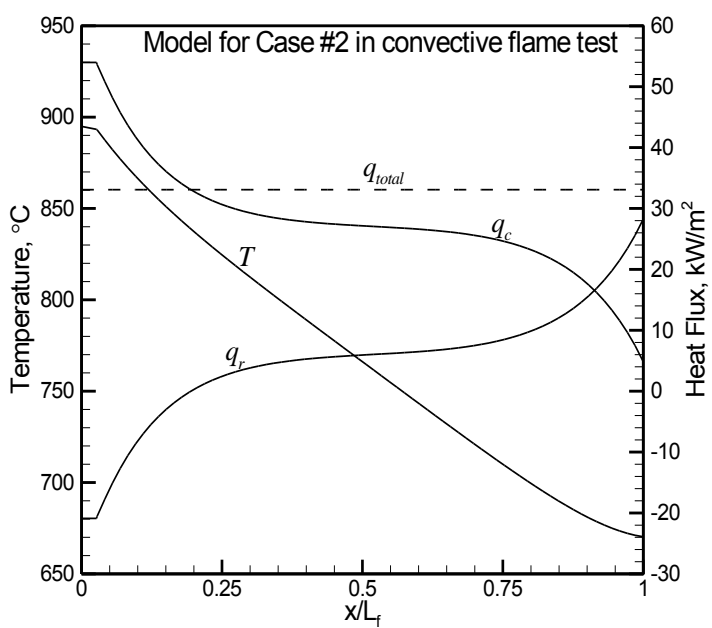

(a)

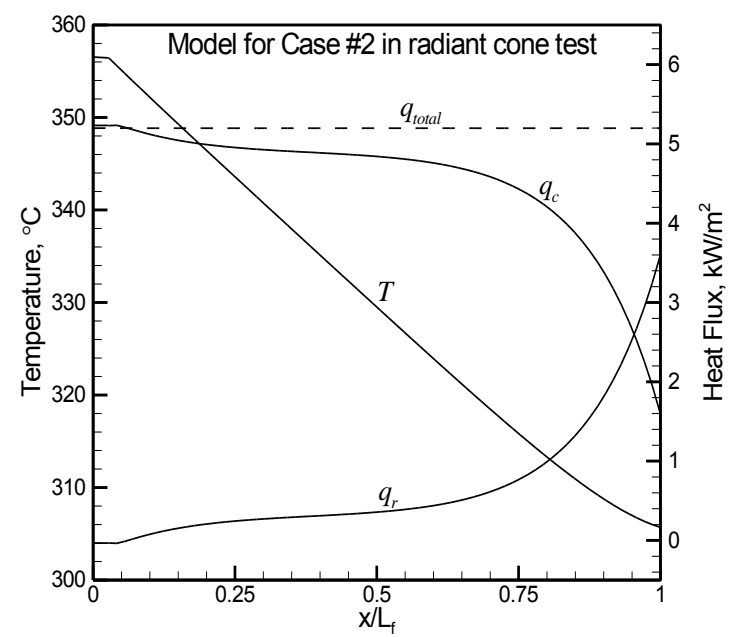

(b)

Fig. 5. Case \#2 in Table 3. The computed distributions of temperature $(T)$, conductive heat flux $\left(q_{c}\right)$ and net radiative heat flux $\left(q_{r}\right)$ in aluminized fiberglass fabric at the steady state in: (a) convective flame test; (b) radiant cone test.

The aluminum foil of high reflectivity has been extensively used in blocking thermal radiation. In Case \#2, an aluminum foil is initially attached to the front side of the fiberglass fabric. Before presenting the computational results, a few words on the aluminum properties are needed. The thermal conductivity of aluminum is much higher than that of the fiberglass, so the temperature difference in such a thin layer is negligible. Basically, the aluminum layer is used to block the radiative heat transfer only. The quoted melting temperature of aluminum is around $660^{\circ} \mathrm{C}$. In many (convective) experiments, no visible trace of the aluminum foil is found on the fabric surface after the tests. The radiative properties for aluminum foil therefore need to be slightly more complicated. In the model, when temperature is lower than $610{ }^{\circ} \mathrm{C}$, it is assumed that the aluminum foil is intact and the extinction coefficient is $2800 \mathrm{~cm}^{-1}$ (approximately 12 times of that of the fiberglass fabric), albedo is 0.93 and the back scattering portion is unity. By using such a large extinction coefficient, the incident radiative heat flux is either scattered or absorbed. This effectively says that the aluminum foil will reflect $93 \%$ of the incident radiative heat flux, which is the reported surface reflectivity for aluminum foil at $300 \mathrm{~K}$. When the temperature is greater than $710{ }^{\circ} \mathrm{C}$, although the aluminum foil is destroyed, the surface properties do not completely go back to the virgin fiberglass case. This is inferred from the experimental HBE values in the convective flame tests, i.e. there is a difference between Cases \#1 and \#2. Apparently, the melting of aluminum causes some change of the fabric radiative properties. Guided by the experimental results in the convective flame test of Case \#2, for temperature greater than $710^{\circ} \mathrm{C}$, the extinction coefficient becomes $380 \mathrm{~cm}^{-1}$. In the temperature range $610^{\circ} \mathrm{C}$ to $710^{\circ} \mathrm{C}$, all the radiative properties are linearly interpolated between the properties at $610{ }^{\circ} \mathrm{C}$ and $710{ }^{\circ} \mathrm{C}$, see Table 2 for the list of all property values used.

Figure 5 and Table 3 present the computed data for Case \#2. The computed and experimental HBEs are close to each other, as expected, since the experimental data were used to calibrate the radiative properties of aluminum melt. The HBEs for the radiant cone cases are high ( 93.7\%) when the aluminum foil is attached to the front surface. With the aluminum foil blocking most of the incident radiation, the fabric temperature is also very low. On the other hand, in the convective flame test, the front surface temperature is high enough to destroy the aluminum foil, but the contaminated new surface blocks a portion of the indepth radiation emission from escaping. Consequently, the radiative loss is less despite having a higher surface temperature. The computed HBE is $60.1 \%$ and is lower than the corresponding case in Case \#1 $(69.7 \%)$.

Double layers of fiberglass fabric and different placement of aluminum foils were also tested and modeled. The four different arrangements are shown in Table 3 Cases \#1'-4'.

As the fabrics are put together, there is uncertainty in the air gap between the layers. Unless otherwise specified, the air gap is assumed to be $0.5 \mathrm{~mm}$ in the model and the property parameters are listed in 
Table 2. The thermal conductivity of air is significantly lower than that of the fiberglass, so the air gap can serve as good blockage on the conductive heat transfer in the blankets. The experimental and simulated HBEs for double-fabric-layer cases for both convective and radiative heating tests are listed in Table 3. In Case \#1' (double layers without aluminum foil), both a $0.5 \mathrm{~mm}$ air gap and a no-gap cases are computed. The no-gap HBE's are presented in the parenthesis. It can be seen that these computed results are reasonably close to the experimental values, especially given the possible variations of air gap distances from one test to the other. It is found that increasing the thickness (especially with an air gap between layers) has a modest effect on improving HBEs.

Case \#2' with aluminum foil placed on the front side also has good comparison on HBEs. Case \#3' with aluminum foil on the back side has a large discrepancy on HBE between the model and experiment for the convective heating case. The computed value is $88.8 \%$ but the measured value is only $79.8 \%$. While there are uncertainties on the aluminum radiative properties in the neighborhood of the melting temperature, there may also be experimental complications. For example, if the aluminum melts, the melted material may sink into the fabric by gravity (the experiments were carried out with heat input from below). This may affect properties in an unknown manner.

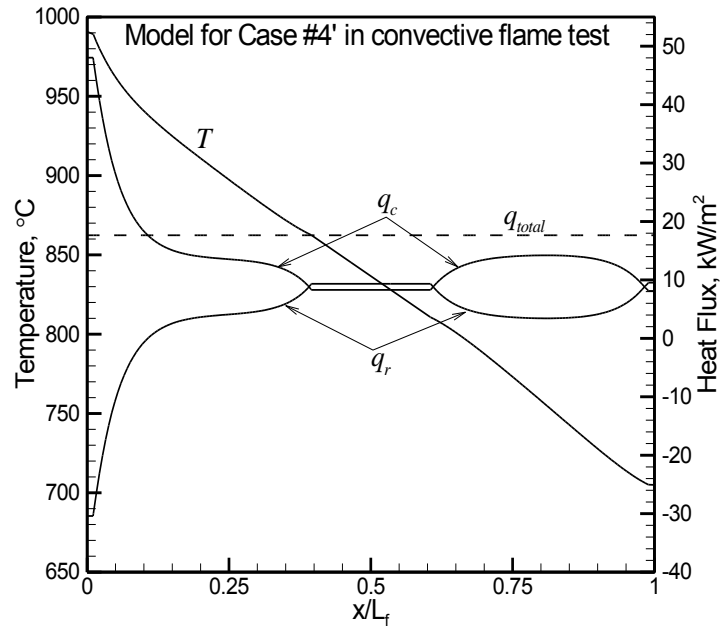

(a)

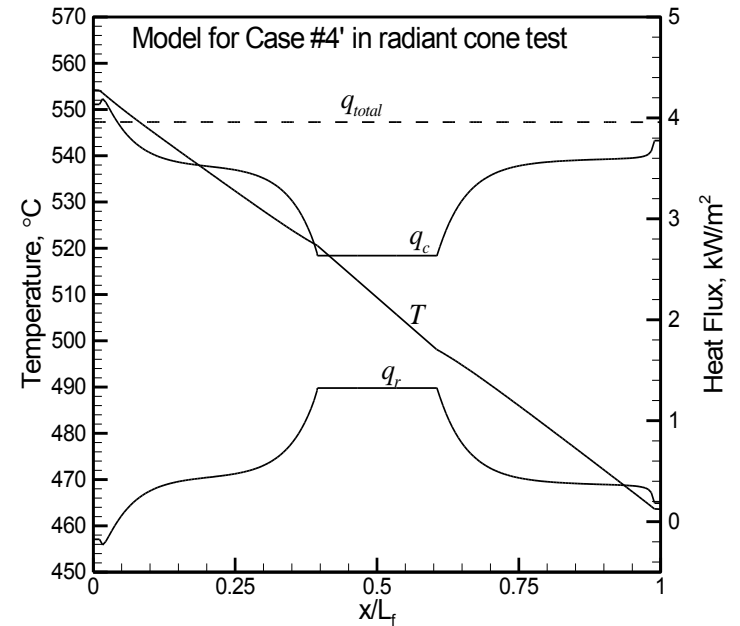

(b)

Fig. 6. Case \#4' in Table 3. The computed distributions of temperature $(T)$, conductive heat flux $\left(q_{c}\right)$ and net radiative heat flux $\left(q_{r}\right)$ along thickness at the steady state in: (a) convective flame test; (b) radiant cone test.

Finally, we have Case \#4' that has double layers of fiberglass fabric and aluminum foils on both the front and back surfaces. This is the best performer experimentally with a convective $\mathrm{HBE}=87.9 \%$ and a radiative $\mathrm{HBE}=96.2 \%$. The computed $\mathrm{HBE}$ for the radiative heating case is close $(95.2 \%$ ) (as a matter of fact, all the computed radiative heating cases are close to the experiments). However, there is also a large difference on the convective HBEs (experiment $87.9 \%$ vs. model $78.8 \%$ ).

The heat flux and temperature distributions for Case \#4' are shown in Fig. 6. For the convective heating case (Fig. 6a), the computed front temperature (at $x=0$ ) reaches $990{ }^{\circ} \mathrm{C}$ and with an air gap between two fabrics, the heat flux distributions in the front fabric is similar to Case \#2 (Fig. 5a). At the back surface of the front fabric, the radiative heat flux becomes somewhat higher than the conductive heat flux. In the air gap, because no existence of a radiative participating medium is assumed the radiative heat flux is uniform, so is the conductive heat flux. As the radiative heat transfers into the back fabric, the radiative heat flux decreases to a minimum due to in-depth absorption and the conductive heat flux shows the opposite trend (similar to Case \#1 in radiaitve cone test (Fig. 4b)). Close to the back surface $\left(x=L_{f}\right)$, Fig 6a shows the radiative heat flux increases due to in-depth emission because the back aluminum foil is destroyed $\left(T_{\text {back }}=705^{\circ} \mathrm{C}\right)$. For the radiatve heating case (Fig. 6b), the front aluminum foil is intact $\left(T_{\text {front }}=554{ }^{\circ} \mathrm{C}\right)$ and reflects most of the incident radiation heat (similar to Cases \#2 and \#2'). In the air gap, the conductive heat flux is still higher than the radiative heat flux since the temperatures are low (compare to the convective 
case (Fig. 6a)). Comparing to the back (overall) temperature in Case \#2' $\left(295{ }^{\circ} \mathrm{C}\right)$, the back (overall) temperature in Case $\# 4^{\prime}\left(464^{\circ} \mathrm{C}\right)$ is significantly higher because the back aluminum foil blocks the radiative heat flux from leaving the fabric. In addition, very close to the back surface, the conductive heat flux greatly increases due to the high conductivity of aluminum.

For convective heating, the front aluminum foil with low emissivity is expected to be destroyed to have higher emission loss while the back aluminum foil tends to be intact because of lower temperatures. It is found that the intact back aluminum foil can block the radiative heat flux in the fabric, increasing the emission loss from the front surface, and then improve the HBE.

\section{CONCLUSIONS}

To investigate the performance of thin fire blanket for house protection from wildland fires, a onedimensional model, which combines conduction and radiation heat transfer, has been developed and the model computation has been carried out to compare with bench-scale experiments. Two types of heat sources are studied: convective heating from a burner flame and radiative heating from a cone heater. The heat blocking mechanism by radiation is critical in the performance of the blankets at high temperatures. The treatment of radiation includes the radiation transfer equation solved by using a discrete ordinate method since in-depth absorbing, emitting and scattering are believed to be important in these thin blanket materials. A number of material combinations were tested including single and double layers of fiberglass fabric with and without aluminum foil on the front and back surfaces. The main conclusions are:

1) High heat blocking efficiencies can be obtained using thin blankets. The main mechanisms to achieve high heat-blocking efficiency in steady or quasi-steady operation are either reflecting the incoming radiation (for the radiant heating case) or radiative loss through emission from the front surface (for the convective heating case).

2) For the same level of incident heat flux, the energy blocking efficiency has been found to be higher for the radiant heating case than the convective heating case. Protecting houses from convective heating is a more difficult challenge.

3) Placing a highly-reflective layer or coating (e.g. aluminum foil) on the front surface of the blanket can result in a high heat-blocking efficiency for the radiant heating case. This has been routinely used in industry.

4) Placing aluminum foil on both the blanket front and back surfaces appear to be a good way to achieve high performance in both radiant and convective heating at high intensities. Tests with double layers of fiberglass fabric with aluminum foil on both sides produce the highest heatblocking efficiencies.

5) Increasing thickness (especially with an air gap between layers) has a modest effect on improving $\mathrm{HBE}$ but at the expense of increasing blanket weight.

6) A heat transfer model can serve as a tool to optimize the performance of fire blankets. More reliable material properties (radiative and otherwise) at elevated temperatures will help to improve the accuracy of the model's prediction and usefulness.

\section{ACKNOWLEDGEMENTS}

This work was supported by the US Department of Homeland Security, the Federal Emergency Management Agency (FEMA), Assistance to Firefighters Grant Program, Fire Prevention and Safety Grant (No. EMW-2007-FP-02677). The fiberglass fabric samples and the thermal conductivity data were provided by Auburn Manufacturing, Inc. Assistance by Jacob Teets, Mallory Miller, Amber Abbott, Timothy Murray and Jason Williams (CWRU) in conducting the experiments is acknowledged.

\section{REFERENCES}

[1] Mell, W.E., and Lawson, J.R., (2000) A Heat Transfer Model for Firefighters' Protective Clothing, Fire Technology 36(1): 39-68, http://dx.doi.org/10.1023/A:1015429820426 
[2] Takahashi, F., T'ien, J.S., and Olson, S.L., "Characterization of Fire Blanket Materials for Suppression and Protection," $6^{\text {th }}$ U.S. National Combustion Meeting, Ann Arbor, MI, May 17-20, 2009.

[3] Takahashi, F., Murray, T.M., Abbott, A., Hsu, S.-Y., T'ien, J.S., and Olson, S.L., "Performance Evaluation Criteria of Fire Blanket Materials for Structure Protection in Wildland-Urban Interface Fires," Fall Technical Meeting of the Eastern State Section of the Combustion Institute, University of Maryland at College Park, Oct. 18-21, 2009.

[4] Takahashi, F., Abbott, A., Murray, T.M., Hsu, S.-Y., T'ien, J.S., and Olson, S.L., "Thermal Protective Performance of Fire Blanket Materials for Structure Protection in Wildland-Urban Interface Fires," Fall Technical Meeting of Western State Section of the Combustion Institute, University of California at Irvine, Oct. 25-27, 2009.

[5] Takahashi, F., Abbott, A., Hsu, S.-Y., T'ien, J.S., and Olson, S.L., "Characterization of Fire Blanket Materials for Structure Protection in Wildland-Urban Interface Fires," Spring Technical Meeting of the Western State Section of the Combustion Institute, University of Colorado at Boulder, Mar. 22-23, 2010.

[6] Takahashi, F., Abbott, A., Murray, T.M., Hsu, S.-Y., T'ien, J.S., and Olson, S.L., "Characteristics of Fire Blanket Materials for Structure Protection in Wildland-Urban Interface Fires," VI International Conference on Forest Fire Research (D. X. Viegas Ed.), Coimbra, Portugal, November 15-18, 2010.

[7] Anon., Standard Test Method for Thermal Protective Performance of Materials for Clothing by Open-Flame Method, ASTM D 4108, American Society for Testing and Materials, 1982.

[8] Anon., Standard Test Method for Heat and Visible Smoke Release Rates for Materials and Products Using an Oxygen Consumption Calorimeter, ASTM E 1354, American Society for Testing and Materials, 2002.

[9] Song, G, Barker, R.L., Hamouda, H., Kuznetsov, A.V., Chitrphiromsri, P., and Grimes, R.V., (2004) Modeling the Thermal Protective Performance of Heat Resistant Garments in Flash Fire Exposures, Textile Res. J. 74(12): 1033-1040, http://dx.doi.org/10.1177/004051750407401201

[10] Chitrphiromsri, P., and Kuznetsov, A.V., (2005) Modeling Heat and Moisture Transport in Firefighter Protective Clothing during Flash Fire Exposure, Heat Mass Transfer 41: 206-215, http://dx.doi.org/10.1007/s00231-004-0504-x

[11] Chitrphiromsri, P., Kuznetsov, A.V., Song, G., and Barker, R.L., (2006) Investigation of Feasibility of Developing Intelligent Firefighter-Protective Garments Based on the Utilization of a Water-Injection System, Numerical Heat Transfer, Part A, 49: 427-450, http://dx.doi.org/10.1080/10407780500359869

[12] Torvi, D.A., and Dale, J.D., (1999) Heat Transfer in Thin Fibrous Materials under High Heat Flux, Fire Technology 35(3): 210-231, http://dx.doi.org/10.1023/A:1015484426361

[13] Torvi, D.A., and Threlfall, T.G., (2006) Heat Transfer Model of Flame Resistant Fabrics During Cooling After Exposure to Fire, Fire Technology 42(1): 27-48, http://dx.doi.org/10.1007/s10694$\underline{005-3733-8}$

[14] Tong, T.W., and Tien, C.L., (1980) Analytical Models for Thermal Radiation in Fibrous insulations, J. of Building Physics 4(1): 27-44, http://dx.doi.org/10.1177/109719638000400102

[15] Petrov, V.A., (1997) Combined Radiation and Conduction Heat Transfer in High Temperature Fiber Thermal Insulation, Int. J. Heat Mass Transfer 40(9): 2241-2247, http://dx.doi.org/10.1016/S0017-9310(96)00242-6

[16] Tong, T.W., and Tien, C.L., (1983) Radiative Heat Transfer in Fibrous Insulations-Part I: Analytical Study", J. Heat Transfer 105(1):70-75, http://dx.doi.org/10.1115/1.3245561 
[17] Incropera, F.P., and DeWitt, D.P., Fundamentals of Heat and Mass Transfer (4 $4^{\text {th }}$ ed.), John Wiley and Sons, New York, 1996, p. 509.

[18] Modest, M.F., Radiative Heat Transfer ( $2^{\text {nd }}$ ed.), Academic Press, 2003, p. 498.

[19] Saboonchi, A., Sutton, W.H., and Love, T.J., (1988) Direct Determination of Gray Participating Thermal Radiation Properties of Insulating Materials, J. Thermophysics and Heat Transfer 2(2): 97-103, http://dx.doi.org/10.2514/3.71

[20] Tong, T.W., Yang, Q.S., and Tien, C.L., (1983) Radiative Heat Transfer in Fibrous InsulationsPart II: Experimental Study, J. Heat Transfer 105(1): 76-81, http://dx.doi.org/10.1115/1.3245562

[21] Lee, S.C., (1990) Scattering phase function for fibrous media, Int. J. Heat Mass Transfer 33(10): 2183-2190, http://dx.doi.org/10.1016/0017-9310(90)90119-F

[22] Anon., Standard Test Method for Steady-State Heat Flux Measurements and Thermal transmission Properties by Means of the Guarded-Hot-Plate Apparatus, ASTM C177-97, ASTM International, 1997. 